\title{
AS EXCEÇÕES E LIMITAÇÕES AOS DIREITOS DO AUTOR E A OBSERVÂNCIA DA REGRA DO TESTE DOS TRÊS PASSOS (three-step-test)
}

\author{
COPYRIGHT: EXCEPTIONS, LIMITATIONS AND THE THREE-STEP-TEST
}

Maristela Basso ${ }^{1}$

\begin{abstract}
Resumo:
Uma reflexão sistemática e normativa das exceções aos direitos de Autor é realizada partindo-se da Convenção da União de Berna, relativa à proteção das obras literárias e artísticas, base dos principais modelos de exceções e limitações aos direitos de Autor, analisando também os demais instrumentos normativos, a exemplo do Acordo TRIPS/OMC.

De maneira sucinta, a "regra dos três passos" (three step test) prevê hipóteses relacionadas ao direito de reprodução por terceiros, uma vez que autoriza exceções e limitações aos direitos autorais.

Pretende-se discutir a temática a partir dos fundamentos da Doutrina da Interpretação Consistente (Doctrine of Consistente Interpretation) e do princípio do Pacta Sunt Servanda, uma vez que a legislação nacional deve estar em harmonia com o regime internacional de proteção à propriedade intelectual de forma a equilibrar direitos autorais (morais e materiais) e interesse público, consubstanciado no acesso a obras protegidas, possibilitando a tutela de questões relacionadas à educação, pesquisa $\mathrm{e}$ acesso à informação. Especial referência é feita à aplicação das exceções e limitações aos direitos de Autor no âmbito da Internet, a partir da interpretação do fair use.

Palavras-chave: Direito de Autor. "Regra dos Três Passos" (Three Step Test). Exceções e limitações. Direito de reprodução por terceiros. Doutrina da Interpretação Consistente. Internet. Fair Use.
\end{abstract}

\begin{abstract}
:
A systematic and regulatory reflection of exceptions to Copyright is held up on the Convention of the Berne Union on the protection of literary and artistic works, base of the main models of exceptions and limitations to copyright, analyzing also the other normative instruments, as TRIPS / WTO.

Briefly, the "three step test" provides assumptions relating to the right of reproduction by third parties, since it authorizes exceptions and limitations to copyright.

The aim is to discuss the topic from the grounds of the Doctrine of Consistent Interpretation and the principle of Pacta Sunt Servanda, given that national legislation must be in harmony with the international system of intellectual property protection in order to balance copyright (moral and material) in the public interest, embodied in access to protected works, enabling the tutelage of issues related to education, research and access to information. Special reference is done to the application of the exceptions and limitations to copyright within the Internet ambit, from the interpretation of fair use.

Keywords: "Three-step test". Exceptions and Limitations. Reproduction Right for third parties. Doctrine of consistent interpretations. Internet. Fair Use.
\end{abstract}

\footnotetext{
Professora Associada. Livre Docente de Direito Internacional da Faculdade de Direito da Universidade de São Paulo.
} 
1. Análise comparativa das exceções/limitações aos direitos de Autor: Considerações introdutórias

A natureza das exceções aos direitos de Autor deve ser considerada, primeiramente, à luz da Convenção de Berna para a proteção das obras literárias, artísticas e científicas (1886), cujas regras servem hoje de base para todas as exceções aos direitos de propriedade intelectual nos tratados concluídos depois dela e cujos princípios e fundamentos foram revigorados no Acordo OMC/TRIPS. Da mesma forma, a Convenção de Berna é base dos principais modelos de exceções e limitações aos direitos autorais contidos nas legislações domésticas.

A norma geral contida na Convenção de Berna, conhecida como a regra do three-step test, guia os legisladores nacionais (e demais intérpretes do Direito) com relação ao direito de "reprodução" por terceiros. Esse teste autoriza exceções/limitações ao direito de Autor e, por conseguinte, o direito de reprodução por terceiros não-autorizados apenas nas seguintes hipóteses:

(i) em certos casos especiais;

(ii) que não conflitem com a exploração comercial normal da obra e,

(iii) não prejudiquem injustificadamente os legítimos interesses do Autor.

2. A relação entre o sistema internacional e o marco legal brasileiro de proteção dos direitos autorais: Aplicação da Doutrina da Interpretação Consistente

\section{A Doutrina da Interpretação Consistente (Doctrine of Consistent} Interpretation) é uma regra de hermenêutica de normas legais nacionais cuja gênese seja internacional. Segundo esta doutrina, ${ }^{2}$ quando uma norma local permitir diferentes interpretações, esta deverá ser interpretada em consonância com as obrigações internacionais pertinentes à matéria, ${ }^{3}$ possibilitando-se uma relação harmônica do sistema jurídico

\footnotetext{
PRINSSEN, Jolande M. Domestic legal effects of EU criminal law: a transfer of EC law doctrines?, p. 7. Artigo apresentado na Conferência "Interface between EU and National Law", Amsterdã, Universidade de Amsterdã, fevereiro, 2006. Disponível em: <http://www.jur.uva.nl/interface/object.cfm/objectid=A2F4A779E278-4FE3-97EE7C5D1701C657/download=true>

3 A Doutrina da Interpretação Consistente foi introduzida, em 1804, pela Suprema Corte dos Estados Unidos da América em decisão proferida no caso Charming Betsy. O juiz Marshall frisou que "uma lei aprovada pelo Congresso nunca deve ser interpretada de forma a violar o direito das gentes, sempre que for possível". A Corte Européia de Justiça, no mesmo sentido, dá à legislação comunitária européia (quando esta estiver sujeita a mais de uma interpretação), tanto quanto possível, uma interpretação que seja consistente com os acordos internacionais de que seja parte a Comunidade Européia (Commission v. Federal Republic of Germany, C-61/94, 1996). A Suprema Corte da Suíça, em 1968, em Frigero v. EVED, também decidiu que a norma nacional deve ser aplicada e interpretada de acordo com as obrigações internacionais pertinentes, sempre que houver dúvidas sobre a interpretação que deva ser dada às normas locais. ABBOT, Frederick; COTTIER,
} 
nacional com o internacional, bem como a realização concreta do princípio do Pacta Sunt Servada 4 que, necessariamente, deve ser observado por todos os órgãos estatais, inclusive pelo Poder Judiciário. ${ }^{5}$ No campo das relações comerciais internacionais, a aplicação da Doutrina da Interpretação Consistente ainda traz a vantagem pragmática de minimizar os riscos do Estado brasileiro vir a ser alvo de litígios internacionais perante o Órgão de Solução de Controvérsias (OSC) da Organização Mundial do Comércio (OMC) e de retaliações comerciais.

O Brasil, na qualidade de País Membro da OMC, assumiu a obrigação de prover (em seu território), aos titulares brasileiros e estrangeiros de direitos autorais, proteção efetiva de acordo com os patamares mínimos de proteção estabelecidos no Acordo ADPIC/TRIPS (Acordo Sobre Aspectos de Direitos de Propriedade Intelectual Relacionados ao Comércio/Trade Related Aspects of Intellectual Property Rights), parte integrante do Acordo Constitutivo da Organização Mundial do Comércio ("OMC”), que se encontra em vigor e incorporado ao ordenamento jurídico brasileiro pelo Decreto n. 1.355. ${ }^{6}$ Os patamares de proteção previstos no Acordo TRIPS, no que concerne à proteção dos direitos autorais, foram construídos sobre a estrutura da Convenção de Berna Relativa à Proteção das Obras Literárias e Artísticas ${ }^{7}$ (Convenção de Berna), conforme disposto no art. $9^{\circ}$ do Acordo TRIPS que dispõe:

"Os Membros cumprirão o disposto nos artigos 1 a 21 e no Apêndice da Convenção de Berna (versão de 1971)". " Uma vez aprovados e promulgados, respectivamente, pelo Congresso Nacional e Chefe do Poder Executivo, os referidos Acordos internacionais passam a integrar o sistema jurídico brasileiro com o status de lei ordinária, tendo aplicação direta e imediata.

Além do Acordo TRIPS e da Convenção de Berna, o regime jurídico brasileiro de proteção dos direitos autorais é ainda composto pela Lei n. 9.610, de 19 de fevereiro de 1998 (Lei de Direitos Autorais - LDA), a qual regulamenta, em âmbito

Thomas; GURRY, Francis. The international intellectual property system: commentary and materials: part one. The Hague-Boston: Kluwer Law International, 1999. p. 558-560.

4 A Convenção de Viena sobre o Direito dos Tratados determina, em seu art. 26, o conteúdo do princípio do Pacta Sunt Servanda: "Todo tratado em vigor obriga as partes e deve ser cumprido por elas de boa fé".

5 Id. Ibid., p. 560-561.

6 Decreto n. 1.355, de 30 de dezembro de 1994, que promulga a Ata Final que incorpora os Resultados da Rodada Uruguai de Negociações Comerciais Multilaterais do GATT.

7 O Decreto n. 75.699, de 6 de maio de 1975, promulga a Convenção da União de Berna, versão revista em Paris a 24 de julho de 1971 .

8 Art. $9^{\circ}$ do Acordo TRIPS da OMC. 
doméstico, a Convenção de Berna e a Seção 1 da Parte II do Acordo TRIPS e a Constituição Federal (art. 5, XXVII).

O regime jurídico brasileiro de proteção dos direitos autorais é composto por dispositivos legais de gênese internacional, notadamente, a Convenção de Berna e o Acordo TRIPS da OMC, bem como por dispositivos de origem nacional - a Constituição Federal do Brasil e a chamada Lei de Direitos Autorais - LDA. Com o objetivo de que a aplicação da LDA não infrinja os direitos dos titulares de direitos autorais decorrentes dos tratados internacionais, preservando-se, pois, o equilíbrio sistêmico que visa ao estabelecimento de um regime que proteja, de um lado, os interesses materiais e morais dos titulares dos direitos autorais (com vistas a fomentar a produção intelectual e científica) e, do outro, os interesses do público de acesso a obras protegidas, o operador/intérprete do Direito deve, em conformidade com a Doutrina da interpretação Consistente, interpretar, observar e aplicar os dispositivos da LDA e da Constituição Federal, em consonância com o estabelecido nos tratados internacionais.

Sob esta ótica, a Convenção de Berna e o Acordo TRIPS da OMC são os cânones de interpretação e aplicação das limitações aos direitos autorais arroladas no art. 46 e seguintes da LDA. Ou seja, as limitações previstas na LDA devem se conformar aos patamares mínimos de proteção dos direitos autorais fixados pela Convenção de Berna e Acordo TRIPS.

3. O equilíbrio sistêmico dos sistemas nacional e internacional de proteção dos direitos autorais: Os direitos exclusivos dos autores e a regra do Teste dos Três Passos (Three-step test)

A Convenção de Berna, concluída em 1886 e revisada em algumas outras ocasiões, ${ }^{9}$ fundou o sistema internacional de proteção dos direitos autorais. O propósito deste sistema é a proteção, e maneira tanto quanto possível, eficaz e uniforme dos direitos dos autores ${ }^{10}$ sobre suas respectivas obras literárias e artísticas, ${ }^{11}$ promovendo, pois, a inovação por intermédio do bloqueio de atividades de apropriação de obras protegidas. $\mathrm{O}$ Sistema de Berna foi profundamente influenciado pela doutrina francesa do droit d'auteur que, por sua vez, tem como fundamentos básicos a doutrina do Direito Natural.

\footnotetext{
9 A respeito da Convenção de Berna para a proteção das obras literárias e artísticas de 1886, vide de BASSO, Maristela. $O$ direito internacional da propriedade intelectual. Porto Alegre: Livraria do Advogado Editora, 2000. p. 90 e ss.

${ }^{10}$ A LDA define Autor como “(...) a pessoa física criadora de obra literária, artística ou científica” (art. 11 da LDA)

${ }^{11}$ Preâmbulo da Convenção de Berna, Revisão de Paris, 1971.
} 
A proteção prevista nos instrumentos internacionais visa à proteção das obras contra atos de apropriação direta (reprodução textual e literal, por exemplo, de uma obra literária, comunicação ao público de obra protegida) e indireta ${ }^{12}$ (adaptação, arranjos e outras transformações da obra original - art. 12, da Convenção de Berna). Historicamente, o cerne da tutela dos interesses dos titulares de direitos autorais é o direito exclusivo de reprodução, mas não se restringe a ele, abrangendo também os direitos de tradução, adaptação e modificações gerais, dentre outros.

A LDA, em seu Título III, Capítulo III, reflete a lógica do sistema internacional de resguardar os interesses econômicos dos titulares de direitos autorais contra apropriação direta e indireta de suas obras. Neste Capítulo, a LDA regula os direitos patrimoniais dos autores e, conseqüentemente, as prerrogativas investidas nos titulares de direitos autorais em relação às suas obras, possibilitando-lhes extrair benefícios financeiros por seus esforços e divulgação de seus trabalhos ao público.

A fim de aclarar com exemplos legais concretos o que ora se afirma, reproduzimos alguns dispositivos da LDA que corporificam o referido princípio geral de proteção contra apropriação direta e indireta de obras protegidas:

"Art. 28. Cabe ao autor o direito exclusivo de utilizar, fruir e dispor da obra literária, artística ou cientifica”.

“Art. 29. Depende de autorização prévia e expressa do autor a utilização da obra, por quaisquer modalidades, tais como: ${ }^{13}$

I - a reprodução parcial ${ }^{14}$ ou integral ${ }^{15}$ (a cópia de um ou vários exemplares de uma obra literária, artística ou científica ou de um fonograma, de qualquer forma

\footnotetext{
${ }^{12}$ LADAS, Stephen P. The international protection of literary and artístic property. New York: The Macmillan Company, 1938. v. 1, p. 566-570. No mesmo sentido ver CORNISH, William; LLEWELYN, David. Intellectual property: patents, copyright, trade marks and allied rights. 5. ed. London: Sweet \& Maxwell, 2003. p. 420 e 422.

13 Os poderes investidos pela LDA nos autores são meramente exemplificativos.

${ }^{14}$ Foi acordado, durante as negociações de Estocolmo, a inserção na Convenção de Berna de um dispositivo que reconhece o direito de reprodução investido nos autores. Sobre a definição do que cabe dentro do direito de reprodução, o Comitê Negocial reconheceu que o direito de reprodução abrange tanto a reprodução parcial quanto integral de obras protegidas. Svante Bergström, Report on the Work of Main Committee I (Substantive Provisions of Berne Convention: Articles 1 to 20). "Records of the Intellectual Property Conference of Stockholm", June 11 to July 14, 1967, Volume II, p. 291.

15 Art. 9.1 da Convenção de Berna, Revisão de 1971 : “Os autores de obras literárias e artísticas protegidas pela presente Convenção gozam do direito exclusivo de autorizar a reprodução destas obras, de qualquer modo ou sob qualquer forma que seja". A LDA, já flexibilizada para abarcar situações infratoras aos direitos autorais no âmbito virtual, define "reprodução" como "a cópia de um ou vários exemplares de uma obra literária, artística ou científica ou de um fonograma, de qualquer forma tangível, incluindo qualquer armazenamento permanente ou temporário por meios eletrônicos ou qualquer outro meio de fixação que venha a ser desenvolvido" (art. $\left.5^{\circ}, \mathrm{VI}\right)$. Logo, reprodução não mais se limita à reprodução tangível de obras protegidas; o armazenamento, mesmo que permanente, de obras protegidas em meios eletrônicos caracteriza também uma reprodução para fins legais.
} 
tangível, incluindo qualquer armazenamento permanente ou temporário por meios eletrônicos ou qualquer outro meio de fixação que venha a ser desenvolvido (...)

VIII - a utilização, direta ou indireta, da obra literária, artística ou científica (...);

IX - a inclusão em base de dados, o armazenamento em computador, a microfilmagem e as demais formas de arquivamento do gênero;

$X$ - quaisquer outras modalidades de utilização existentes ou que venham a ser inventadas ${ }^{16}$."

“Art. 33. Ninguém pode reproduzir obra que não pertença ao domínio público, a pretexto de anotá-la, comentá-la ou melhorá-la, sem permissão do autor”. (Grifamos)

Ademais, o sistema internacional de proteção dos direitos autorais visa também alcançar um equilíbrio entre os interesses privados (dos autores e empresas cujas atividades dependem destes direitos) e públicos de acesso às obras protegidas. Neste sentido, a Convenção de Berna e o Acordo TRIPS autorizam seus Estados-partes a estabelecerem limitações aos direitos patrimoniais dos autores com vistas à promoção de determinadas políticas públicas.

A norma geral do Teste dos Três Passos (three-step test), que regula e norteia as limitações aos direitos exclusivos dos autores, foi introduzida na Convenção de Berna, em 1967, durante a revisão de Estocolmo, estando atualmente prevista no art. 9.2 da Convenção de Berna (revisão de Paris) e no art. 13 do Acordo TRIPS da OMC, conforme se lê:

“Art. 9.2 da Convenção de Berna

2) Às legislações dos países da União reserva-se a faculdade de permitir a reprodução das referidas obras em certos casos especiais, contanto que tal reprodução não afete a exploração normal da obra nem cause prejuízo injustificado aos interesses legítimos do autor”.

\section{“Art. 13 do Acordo TRIPS da OMC}

\footnotetext{
${ }^{16} \mathrm{Na}$ atualidade do direito nacional e internacional, são reservados aos titulares de direitos autorais, com exclusividade, todos os atos de reprodução de um trabalho, tanto direta quanto indiretamente, de qualquer maneira ou forma, incluindo o armazenamento digital; qualquer digitalização de uma obra protegida, upload ou download de obras de um servidor para outro, cópias incidentais criadas no curso do uso de um computador. Neste sentido, GUIBAULT, Lucie. Discussion paper on the question of exceptions to and limitations on copyright and neighbouring rights in the digital era. "Council of Europe", outubro de 1998. Disponível em: $<$ http://www.ivir.nl/publications/guibault/final-report.html\#note75>.
} 
Os Membros restringirão as limitações ou exceções aos direitos exclusivos a determinados casos especiais, que não conflitem com a exploração normal da obra e não prejudiquem injustificavelmente os interesses legítimos do titular do direito”. (Grifamos)

Até a adoção da regra do Teste dos Três Passos, os Estados-partes da Convenção de Berna adotavam um sem número de limitações aos direitos autorais que, não raramente, esvaziavam os direitos patrimoniais dos titulares de direitos autorais. Um dos objetivos das negociações de Estocolmo foi o de estabelecer uma regra geral que fosse cumprida por toda e qualquer limitação aos direitos autorais, ou seja, os Estadospartes da Convenção de Berna manteriam a discricionariedade para estabelecer exceções aos direitos autorais, entretanto, estas necessariamente deveriam preencher as condições fixadas pelo art. 9.2 da Convenção de Berna. O exame dos anais das negociações de Estocolmo esclarece que o fundamento do Teste dos Três Passos é o de impedir que as obras reproduzidas sob os auspícios das limitações aos direitos autorais entrem em competição, direta ou indireta, com a obra introduzida no mercado diretamente ou com o consentimento do titular de direitos autorais. ${ }^{17}$

A questão que se insurge é qual seria a razão da transposição/repetição do “Teste dos Três Passos” da Convenção de Berna para o Acordo TRIPS da OMC?

No âmbito de Berna, o "Teste dos Três Passos" é aplicável apenas às limitações ao direito de reprodução. O Acordo TRIPS, por sua vez, expande o escopo de aplicação do "Teste dos Três Passos" para todas as limitações aos direitos exclusivos dos titulares de direitos autorais, ou seja, mesmo as limitações explicitamente arroladas na Convenção de Berna - as chamadas exceções jure conventionium - deverão ser avaliadas pelo "Teste dos Três Passos" antes de serem observadas no caso concreto.

Conseqüentemente, todas as limitações aos direitos patrimoniais dos titulares de direitos autorais arrolados no Título III, Capítulo III da LDA deverão passar pelo crivo do Teste dos Três Passos antes de sua aplicação. Daí porque, o Brasil, na condição de signatário tanto da Convenção de Berna quanto do Acordo TRIPS, deve pautar a aplicação das limitações (exceções) aos direitos autorais previstas na LDA ao Teste dos Três Passos.

Corroborando tal interpretação, podemos identificar o conteúdo do Teste dos Três Passos de modo claro no art. 46, VIII da LDA que dispõe:

a reprodução, em quaisquer obras, de pequenos trechos de obras preexistentes, de qualquer natureza, ou de obra

\footnotetext{
17 UNCTAD - ICTSD. Resource Book on TRIPS and Development. Cambridge: Cambridge University Press, 2005. p. 192.
} 
integral, quando de artes plásticas, sempre que a reprodução em si não seja o objetivo principal da obra nova ${ }^{I 8}$ e que não prejudique a exploração normal da obra reproduzida nem cause um prejuizo injustificado aos legitimos interesses dos autores. (Grifamos)

A regra do Teste dos Três Passos reflete a necessidade de se manter o equilíbrio entre os direitos dos autores e o interesse do grande público, isto é, interesses relacionados à educação, pesquisa e acesso à informação. ${ }^{19}$

À luz da Doutrina da Interpretação Consistente, o Teste dos Três Passos é a diretriz que deve ser empregada pelo operador/intérprete/aplicador da LDA para a definição do escopo das limitações e sua aplicação, no caso concreto, a fim de não se causar um prejuízo injustificado aos interesses legítimos dos autores e empresas cujas atuações sejam intimamente dependentes dos direitos autorais e, por último, mas não menos importante, para não se infringir obrigações internacionais assumidas pelo Brasil cujo desrespeito pode sujeitá-lo a retaliações comerciais no âmbito do Sistema da Organização Mundial do Comércio. Neste sentido é o entendimento da OMC, conforme relatório do Painel no caso United States - Section 110(5) of US Copyright Act (DS 160).

Detêmo-nos, ainda que em passos largos, na decisão do Órgão de Solução de Controvérsias da OMC.

3.1. Organização Mundial do Comércio e a regra do Teste dos Três Passos - Padrão para a avaliação das limitações/exceções aos direitos dos autores

Em 26 de janeiro de 1999, imediatamente após a aprovação pelo Congresso norte-americano da lei Fairness in Music Licensing Act que emenda o US Copyright Act (Lei de Direitos Autorais dos EUA), a Comunidade Européia ${ }^{20} 19$ iniciou o processo de consultas com os EUA com a finalidade de discutir a legalidade da referida legislação em face do Acordo TRIPS, notadamente, em relação ao Teste dos Três Passos (art. 13 - referido acima).Pela falta de acordo entre as partes, a Comunidade Européia solicitou à OMC a instauração de Painel especial cuja função foi a de analisar, especificamente, se as exceções aos direitos exclusivos dos autores, previstas na seção 110 (5), alíneas A e

\footnotetext{
18 “A reprodução de pequenos trechos de obras preexistentes, sempre que a reprodução em si não seja o objetivo principal da obra nova" constitui alegadamente um caso especial, nos termos da Convenção de Berna e Acordo TRIPS

19 GUIBAULT, Lucie. op. cit.

${ }^{20} \mathrm{Na}$ linguagem da Organização Mundial do Comércio, a União Européia é designada como Comunidade Européia.
} 
B do US Copyright Act, emendada em 1998, estavam em consonância com o art. 13 do Acordo TRIPS. As disposições americanas autorizavam, respectivamente: (i) pequenas empresas locais a transmitirem publicamente, por meio de aparelhos de televisão e rádios, programas, vídeos, musicais, músicas, enfim obras de entretenimento para seus clientes, sem o recolhimento de taxas (“homestyle exception”); (ii) a condução das mesmas atividades por "certas empresas de pequeno porte" (“business exception").

Em junho de 2000, a OMC publicou relatório ${ }^{21}$ avaliando a demanda proposta pela Comunidade Européia contra os Estados Unidos, baseada na infração do art. 13 do Acordo TRIPS pela seção 110(5) do US Copyright Act. O painel considerou que o Teste dos Três Passos é a norma padrão para avaliação da legalidade das limitações aos direitos autorais fixadas pelos Estados-membros da OMC. Desta forma, considerou infração ao art. 13 do Acordo TRIPS a limitação "business exception", que eximia do pagamento de taxas de licenciamento os atos de transmissão de obras protegidas em um número relevante de estabelecimentos comerciais. A limitação "homestyle exception", por sua vez, ao eximir apenas uma parcela comercialmente insignificante de estabelecimentos comerciais, foi considerada legítima.

Um dos aspectos mais interessantes do relatório do Painel é o reconhecimento de que toda e qualquer exceção/limitação aos direitos autorais para ser legal, no âmbito do sistema internacional de comércio, deverá sempre passar pelo crivo do Teste dos Três Passos, incluindo-se mesmo aquelas exceções previstas textualmente na Convenção de Berna. ${ }^{22}$ Tendo em vista que esta foi a primeira vez que a regra do Teste dos Três Passos foi avaliada por uma autoridade intergovernamental (OMC), desde o seu estabelecimento em 1967 pela revisão à Convenção de Berna, entendemos que deve ser seguida a interpretação dada pela Organização Mundial do Comércio, no que concerne às limitações/exceções aos direitos autorais.

\section{Aplicação das exceções/limitações aos direitos de Autor no âmbito da Internet}

O US Digital Millenium Copyrigth Act (1998) introduziu uma camada completamente diferente de direitos: direito de acesso. O quê este novo direito implica de mudança na aplicação das exceções aos direitos de autor? O que se entende por justo manuseio da obra de outrem e acesso à obra?

\footnotetext{
${ }^{21}$ O relatório do caso DS 160 está disponível em: <http://www.wto.org/english/tratop_e/dispu_e/cases_e/ ds160_e.htm>.

${ }^{22}$ OLIVER, Jo. Copyright in the WTO: the panel decision on the three-step test. Nova York: Columbia Journal of Law \& the Arts, 2002.
} 
Se for possível, desde já, admitir uma premissa fundamental de raciocínio, o fair use reflete um conjunto apropriado de critérios para determinar o equilíbrio entre os direitos dos titulares e as necessidades e interesses do usuário. O fair use é uma limitação aos direitos do Autor, isto é, um teste para determinar se o uso do material protegido por tais direitos, enquanto não-autorizado pelo titular, constitua ou-não ato de violação.

O unfair use ou uso não justificado, portanto, é aquele que fere os direitos protegidos pelo direito de Autor. Implica todo uso que não preenche os estágios do threestep test, isto é: (i) não se caracteriza como uso especial/excepcional; (ii) interfere na exploração comercial normal da obra e (iii) causa prejuízo injustificado aos interesses legítimos do titular do direito.

Em outras palavras, qualquer uso que venha a reduzir, comprovada e consideravelmente, os benefícios financeiros que o titular do direito poderia "razoavelmente" obter sob circunstâncias comerciais normais seria, então, “injusto", sem autorização.

Certamente, aqui é fundamental verificar o modo pelo qual podem ser mensuradas a "irrazoabilidade" (considerando-se o "prejuízo injustificado") e a "ingerência” sobre a exploração comercial normal da obra. A questão que se levanta não deve ser apenas se o usuário ganhou "valor" por ter deixado de remunerar o titular do direito pelo uso feito, mas se o usuário teria obtido o material desejado por meio de uma transação comercial qualquer.

Não há dúvida de que o Autor tem direito sobre qualquer uso significativo do ponto de vista comercial - uso que normalmente seria objeto de uma transação comercial.

Em sintese: A abordagem aqui sugerida tem a vantagem de ser compatível com os tratados internacionais vigentes sobre a matéria de direitos de Autor e com os direitos domésticos que podem ser considerados na vanguarda das questões relacionadas ao direito de Autor e o uso da obra para fins transformativos.

Toda vez que um dos steps da regra dos três passos for infringido, não se dirigindo o uso da obra para fins de interesse público, ${ }^{23}$ estaremos diante de violação aos direitos fundamentais dos autores de auferirem benefícios a partir de seus trabalhos,

\footnotetext{
${ }^{23}$ Hipóteses que não visam à informação ao consumidor (objetivo político/de interesse público). Art. 46. Não constitui ofensa aos direitos autorais: I. A reprodução: a) na imprensa diária ou periódica, de notícias ou de artigo informativo, publicado em diários ou periódicos, com a menção do nome do autor, se assinado, e da publicação de onde foram transcritos....".
} 
consoante o disposto no art. $5^{\circ}$, incisos $\mathrm{XVII}^{24}$ e XXIX ${ }^{25}$, da Constituição Federal, de 1988.

São Paulo, dezembro de 2007.

\section{Referências}

ABBOT, Frederick; COTTIER, Thomas; GURRY, Francis. The international intellectual property system: commentary and materials: part one. The Hague-Boston: Kluwer Law International, 1999.

BASSO, Maristela. O direito internacional da propriedade intelectual. Porto Alegre: Livraria do Advogado Editora: 2000.

BERGSTÖM, Svante. Report on the Work of Main Committee I (Substantive Provisions of Berne Convention: Articles 1 to 20). In: RECORDS OF THE INTELLECTUAL PROPERTY CONFERENCE OF STOCKHOLM, 1967, June 11 to July 14, 1967. v. 2, p. 291.

CORNISH, William, LLEWELYN, David. Intellectual property: patents, copyright, trade marks and allied rights. 5. ed. London: Sweet \& Maxwell, 2003.

GUIBAULT, Lucie. Discussion paper on the question of exceptions to and limitations on copyright and neighbouring rights in the digital era. In: Council of Europe, 1998, Strasbourg. Disponível em: $<$ http://www.ivir.nl/publications/guibault/final-report.html\#note75>.

LADAS, Stephen P. The international protection of literary and artistic property. New York: The Macmillan Company, 1938. v. 1.

OLIVER, Jo. Copyright in the WTO: The Panel Decision on the Three-Step Test. Nova York: Columbia Journal of Law \& the Arts, 2002.

PRINSSEN, Jolande M. Domestic legal effects of EU criminal law: a transfer of EC law doctrines?In: Conferência “Interface between EU and National Law”, 2006, Amsterdã: Universidade de Amsterdã. Disponível em: <http://www.jur.uva.nl/interface/object.cfm/objectid=A2F4A779-E278-4FE397EE7C5D1701C657/download=true $>$.

UNCTAD - ICTSD. Resource Book on TRIPS and Development. Cambridge: Cambridge University Press, 2005.

24 “Aos autores pertence o direito exclusivo de utilização, publicação ou reprodução de suas obras...”.

25 “A lei assegurará aos autores de inventos industriais privilégio temporário para sua utilização, bem como proteção às criações industriais, à propriedade de marcas, aos nomes de empresas e a outros signos distintivos..." 